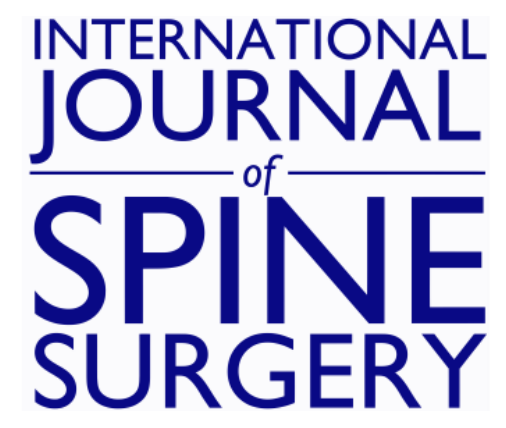

\title{
Biomechanics of an Expandable Lumbar Interbody Fusion Cage Deployed Through Transforaminal Approach
}

Michael Conti Mica, Leonard I. Voronov, Gerard Carandang, Robert M. Havey, Bartosz Wojewnik and Avinash G. Patwardhan

Int J Spine Surg 2017, 11 (4)

doi: https://doi.org/10.14444/4024

http://ijssurgery.com/content/11/4/24

This information is current as of April 26, 2023.

Email Alerts Receive free email-alerts when new articles cite this article. Sign up at:

http://ijssurgery.com/alerts

The International Journal of Shing Surgerih 2397 Waterbury Circle, Suite 1,

Aurora, IL 60504, Phone: +1-630-375-1432

(C) 2017 ISASS. All Rights Reserved. 


\section{Biomechanics of an Expandable Lumbar Interbody Fusion Cage Deployed Through Transforaminal Approach}

Michael Conti Mica, MD, ${ }^{1}$ Leonard I. Voronov, MD, PhD, 1,2 Gerard Carandang, MS,2 Robert M. Havey, MS,1,2 Bartosz Wojewnik, MD, 1 Avinash G. Patwardhan, Ph.D.1,2

${ }_{1}^{1}$ Department of Orthopaedic Surgery and Rehabilitation, Loyola University Medical Center, Maywood, Illinois, 2 Musculoskeletal Biomechanics Laboratory, Department of Veterans Affairs, Edward Hines Jr. VA Hospital, Hines, Illinois.

\section{Abstract}

Introduction

A novel expandable lumbar interbody fusion cage has been developed which allows for a broad endplate footprint similar to an anterior lumbar interbody fusion (ALIF); however, it is deployed from a minimally invasive transforaminal unilateral approach. The perceived benefit is a stable circumferential fusion from a single approach that maintains the anterior tension band of the anterior longitudinal ligament.

The purpose of this biomechanics laboratory study was to evaluate the biomechanical stability of an expandable lumbar interbody cage inserted using a transforaminal approach and deployed in situ compared to a traditional lumbar interbody cage inserted using an anterior approach (control device).

\section{Methods}

Twelve cadaveric spine specimens (L1-L5) were tested intact and after implantation of both the control and experimental devices in two (L2-L3 and L3-L4) segments of each specimen; the assignments of the control and experimental devices to these segments were alternated. Effect of supplemental pedicle screw-rod stabilization was also assessed. Moments were applied to the specimens in flexion-extension (FE), lateral bending (LB), and axial rotation (AR). The effect of physiologic preload on construct stability was evaluated in FE. Segmental motions were measured using an optoelectronic motion measurement system.

\section{Results}

The deployable expendable TLIF cage and control devices significantly reduced FE motion with and without compressive preload when compared to the intact condition $(\mathrm{p}<0.05)$. Segmental motions in LB and AR were also significantly reduced with both devices $(\mathrm{p}<0.05)$. Under no preload, the deployable expendable TLIF cage construct resulted in significantly smaller FE motion compared to the control cage construct $(\mathrm{p}<0.01)$. Under all other testing modes ( $F E$ under $400 \mathrm{~N}$ preload, $\mathrm{LB}$, and $\mathrm{AR}$ ) the postoperative motions of the two constructs did not differ statistically $(\mathrm{p}>0.05)$. Adding bilateral pedicle screws resulted in further reduction of ROM for all loading modes compared to intact condition, with no statistical difference between the two constructs $(p>0.05)$.

\section{Conclusions}

The ability of the deployable expendable interbody cage in reducing segmental motions was equivalent to the control cage when used as a stand-alone construct and also when supplemented with bilateral pedicle screw-rod instrumentation. The larger footprint of the fully deployed TLIF cage combined with preservation of the anterior soft-tissue tension band may provide a better biomechanical fusion environment by combining the advantages of the traditional ALIF and TLIF approaches.

BIOMECHANICS

KEYWORDS: LUMBAR SPINE, EXPANDABLE CAGE, TLIF, FUSION, BIOMECHANICS

VOLUME 11 ISSUE 4 DOI: 10.14444/4024

PAGES 193 - 200

\section{Introduction}

Surgical instrumentation used in fusion surgery for treating lumbar degenerative disc disease aims to im-

prove spinal segment stability, provide indirect decompression for pain relief, and correct deformity. A common surgical treatment option includes use of a lumbar interbody fusion cage or graft, with or withDownloaded from http://ijssurgery.com/ by guest on April 26, 2023 
out supplemental plate or pedicle screw fixation. Posterior lumbar interbody fusion (PLIF), transforaminal lumbar interbody fusion (TLIF), and anterior lumbar interbody fusion (ALIF) using interbody spacers (cages) and bone graft are some of the common forms of instrumented single-level lumbar fusion constructs for the treatment of painful degenerative disc disease with neurological compression. ${ }^{1-3}$

Of these surgical options, ALIF implants are considered desirable due to improved visualization for endplate preparation and the relatively large implant footprint. ${ }^{4}$ TLIF and lateral interbody fusion have garnered recent interest due to their minimally invasive nature and improved segmental biomechanical stability. ${ }^{5-10}$ This stability is attributed to retention of the anterior and posterior longitudinal ligaments, annulus fibrosis, and the facet joints, as well as the large implant footprint when discussing lateral implants. Subsequent lumbar expandable interbody devices have been introduced to facilitate minimally invasive interbody fusion. ${ }^{11}$

There is consensus in the literature that a greater degree of immobilization at the intended fusion levels confers a more ideal environment for boney fusion. Excessive motion interferes with the biologic process of bone healing and results in pseudarthrosis or nonunion. ${ }^{12,13}$ The mechanical environment conducive to promoting biologic fusion depends on the construct rigidity, which is defined as the ability of the fusion construct to limit intervertebral motion while the segment is subjected to physiologic forces and moments during activities of daily living. In the context of constructs that use interbody spacers such as cages, the construct rigidity, in turn, will depend on the footprint of the interbody cage. Secondly, a larger footprint of the interbody cage will distribute the forces going through the anterior column over a larger area of the vertebral endplates, thereby reducing the likelihood of subsidence while providing a larger space for bone graft placement.

The ALIF technique allows the use of an interbody cage with a larger footprint as compared to the traditional PLIF or TLIF cages; however, it requires resection of the anterior tension band (ALL and anterior annulus). TLIF cages can be implanted using a
MIS techniques and allow for the retention of the anterior tension band. However, the small window between the exiting and traversing nerve roots limits the footprint size of the cage. Thus, a larger cage footprint and the necessity of disruption of the soft tissue tension band for cage insertion are two competing factors that influence the interbody cage construct rigidity. When posterior decompression surgery is required, the ability to place a cage with a large footprint through a posterior approach may provide an alternative to a " 360 " surgery necessitating an additional anterior surgical exposure.

The purpose of this study was to evaluate the biomechanical stability of a deployable and expandable lumbar interbody cage (Luna 360, Benvenue Medical, Inc., Santa Clara, CA) inserted through a transforaminal approach and deployed in situ to a traditional lumbar interbody cage inserted using an anterior approach ("control" device). Both implants were tested in stand-alone constructs and with the addition of bilateral pedicle screws and rods.

\section{Material and Methods}

\section{Specimens and Experimental Setup}

Twelve fresh frozen human cadaveric lumbar spine specimens (L1-L5) were used for this study (10 male, 2 female, age $47.5 \pm 10.6)$. Radiographic screening was performed to exclude specimens with fractures, metastatic disease, bridging osteophytes, or other conditions that could affect the biomechanics of the spine. The specimens were thawed and dissected free of their paraspinal musculature while preserving the discs, facet joints, and osteoligamentous structures. The specimens were wrapped in saline soaked gauze to prevent dehydration of the soft tissues. All tests were performed at room temperature.

The specimens were fixed to the apparatus at the caudal-most vertebral body (L5) and were free to move in any plane at the cranial end (L1) (Figure 1). Bending moments were applied in flexion-extension and lateral bending by controlling the flow of water into bags attached to loading arms fixed to the L1 vertebra. In axial rotation, pure moment loading was applied by using two bags acting tangentially to a $30 \mathrm{~cm}$ diameter disc attached to L1. The apparatus allowed 
continuous cycling of the specimen between specified maximum moment endpoints in flexion, extension, lateral bending, and axial rotation. The loaddisplacement data were collected until two reproducible load-displacement loops were obtained.

The angular motion of the L1 to L5 vertebrae were measured using an optoelectronic motion measurement system (Model Certus, Optotrak, Northern Digital, Waterloo, Ontario). In addition, bi-axial angle sensors (Model 902-45, Applied Geomechanics, Santa Cruz, CA) were mounted on each vertebra to allow real-time feedback for the optimization of the preload path. A six-component load cell (Model MC3A-6-1000, AMTI Multi-component transducers, AMTI Inc., Newton, MA) was placed under the specimen to measure the applied compressive preload and moments. Fluoroscopic imaging (GE OEC 9800 Plus digital fluoroscopy machine) was used to document intact disc heights and implant placement.

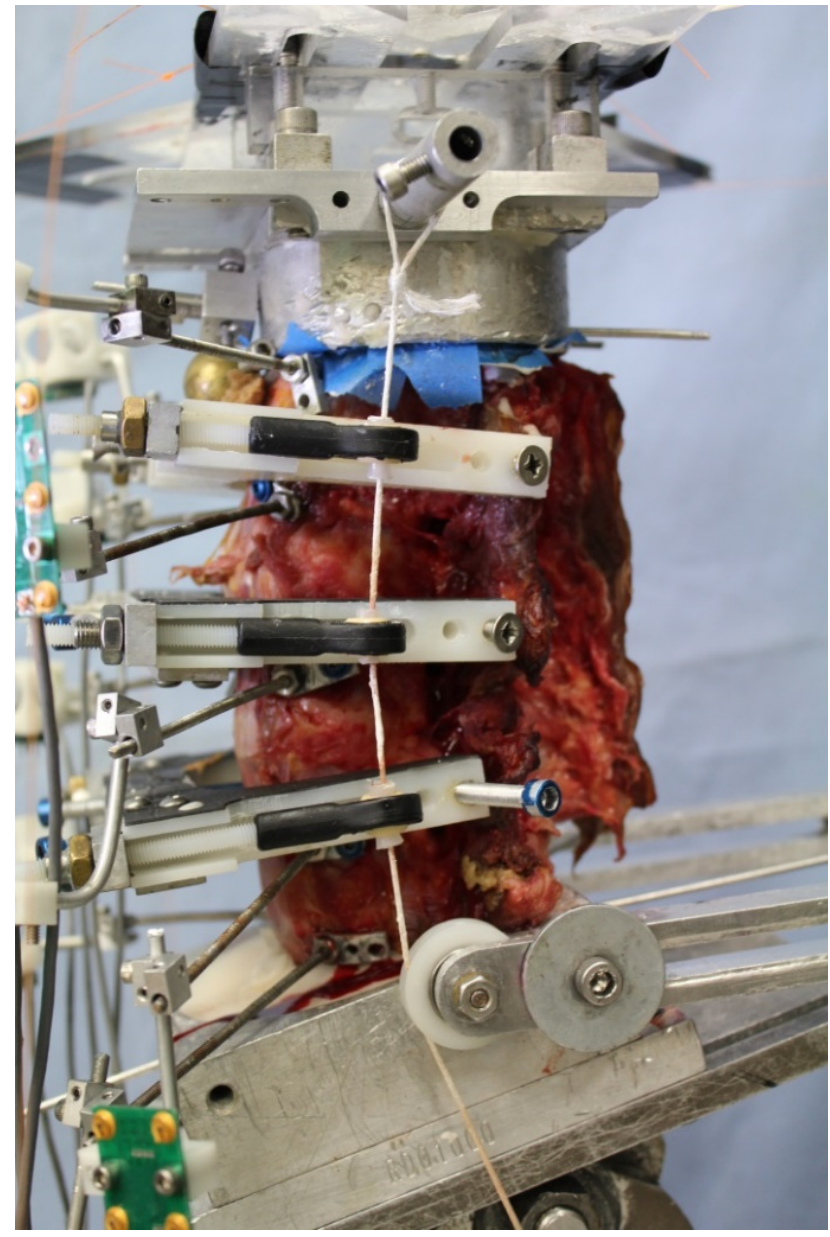

Fig. 1. Lumbar spine (L1-L5) experimental set-up showing compressive follower preload cables and guides.

\section{Experimental Protocol}

Each specimen was tested in flexion $(8 \mathrm{Nm})$ and extension $(6 \mathrm{Nm})$ under $400 \mathrm{~N}$ of follower preload as well as without preload. ${ }^{14-18}$ Each specimen was also tested in lateral bending $( \pm 6 \mathrm{Nm})$ and axial rotation $( \pm 5 \mathrm{Nm})$ without preload. Specimens were tested under the following sequential conditions (Figure 2):

\section{Intact spine}

2. Stand-alone ALIF cage (at L3-L4 for specimens 1-6, at L2-L3 for specimens 7-12)

3. ALIF cage + Bilateral Pedicle Screws (at L3-L4 for specimens 1-6, at L2-L3 for specimens 7-12) 4. Stand-alone Luna TLIF cage inserted transforaminally and expanded in situ (at L2-L3 for specimens 1-6, at L3-L4 for specimens 7-12) (Figure 3) 5. Luna TLIF cage + Bilateral Pedicle Screws (at L2-L3 for specimens 1-6, at L3-L4 for specimens $7-12)$

Thus, 12 segments were implanted with control ALIF cages; six at L2-L3 and six at L3-L4. Similarly, 12 segments were implanted with deployable and expandable cages; six at L2-L3 and six at L3-L4.

\section{Surgical Technique}

The ALIF "control" cage was implanted according to company surgical technique guidelines. A window matching the cage width was made in the anterior annulus and anterior longitudinal ligament. Disc mater-

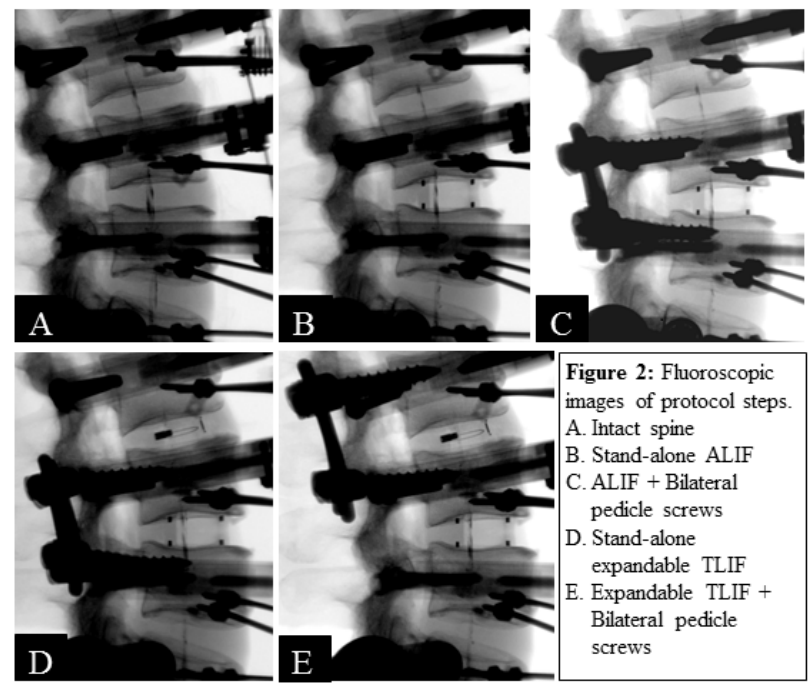

Fig. 2. Fluoroscopic images of protocol steps: 1) Intact spine; 2) Stand-alone ALIF 3) ALIF + Bilateral pedicle screws; 4) Stand-alone expandable TLIF; 5)Expandable TLIF + Bilateral pedicle screws. 
ial was removed and the vertebral endplates were prepared in a conventional fashion while preserving their mechanical integrity. Trial sizing aided by fluoroscopy was performed to select the proper cage size.

Implantation of a deployable and expandable lumbar interbody fusion device (Luna 360, Benvenue Medical, Inc., Santa Clara, CA), was performed using the standard transforaminal approach. A small window was made in the posterolateral annulus. Disc material was removed to allow sufficient room for the device to be deployed. The device was then deployed in situ to produce its axial footprint, and finally expanded, effectively distracting the intervertebral disc space (Figure 4). Once deployed, the implant presents a graft window that allows bone graft material to be inserted post-expansion; however, no bone graft mater-

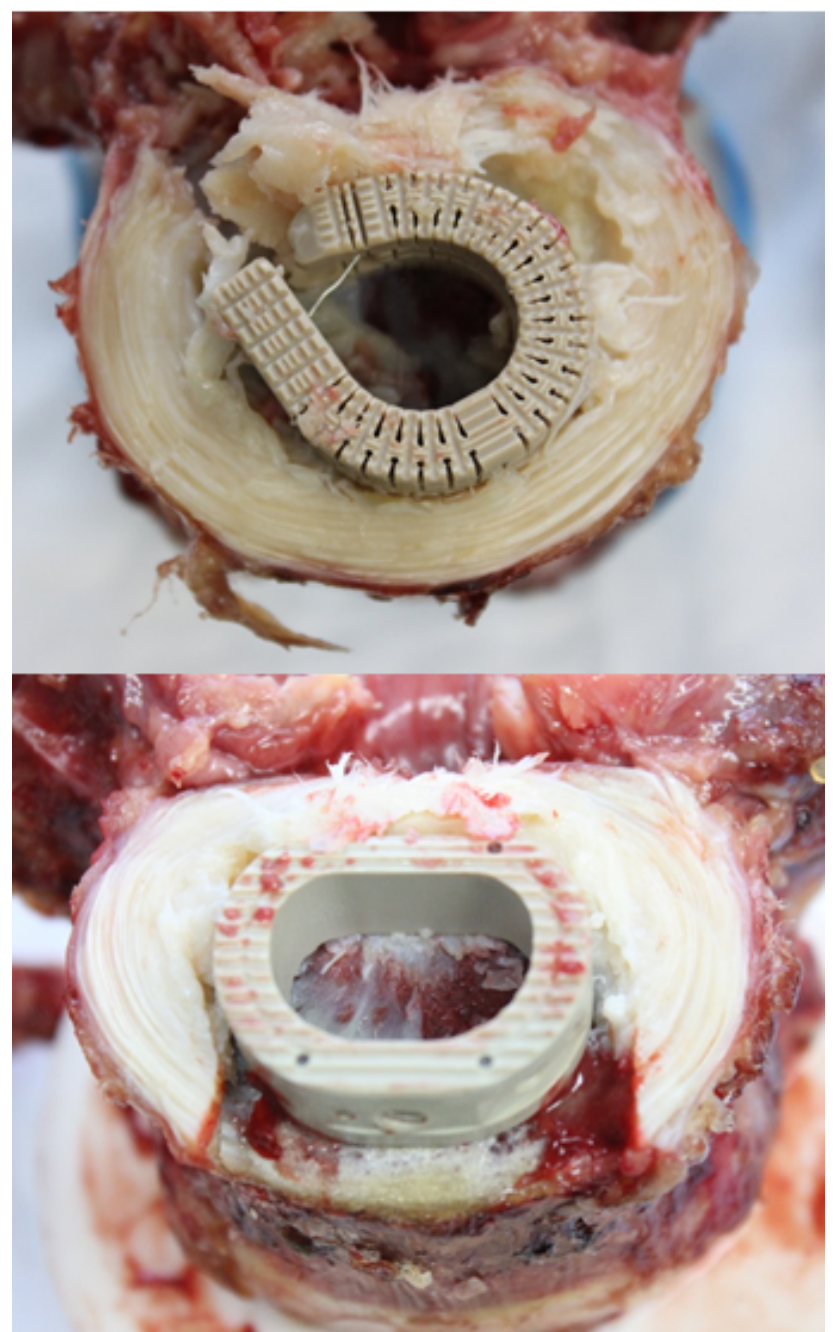

Fig. 3. View of inferior endplates and implant placements after sectioning of intervertebral disc. A) Expandable TLIF cage showing the posterior approach. B) ALIF cage showing the anterior approach. ial was utilized for this biomechanical assessment.

\section{Statistical Analysis}

The applied moment versus vertebral motion data were analyzed using standard methods of rigid body kinematics. ${ }^{19}$ Segmental ranges of motion values were analyzed using paired-sample t-tests. The following comparisons were made:

1. Combined control cage $(\mathrm{n}=12)$ vs Combined deployable and expandable cage $(\mathrm{n}=12)$

2. Combined control cage + PS $(n=12)$ vs Combined deployable and expandable cage + PS $(n=12)$.

These comparisons were done separately for flexionextension, lateral bending, and axial rotation, since no comparisons across load-types were intended in the study design. The statistical data analyses performed with use of the Systat 10.2 software package (Systat Software, Richmond, CA).

\section{Results}

When used as a stand-alone device, the deployable and expandable TLIF cage significantly reduced motion in flexion-extension, from $7.1 \pm 1.1$ degrees to 3.3 \pm 1.3 degrees under no preload, $\mathrm{p}<0.01$, and from 7.1 \pm 1.1 degrees to $3.1 \pm 1.1$ degrees under $400 \mathrm{~N}$ preload, $\mathrm{p}<0.01$ (Table 1). This represents a decrease in sagittal plane motion by 53\% and 57\%, respectively. The control cage also significantly reduced flexion-

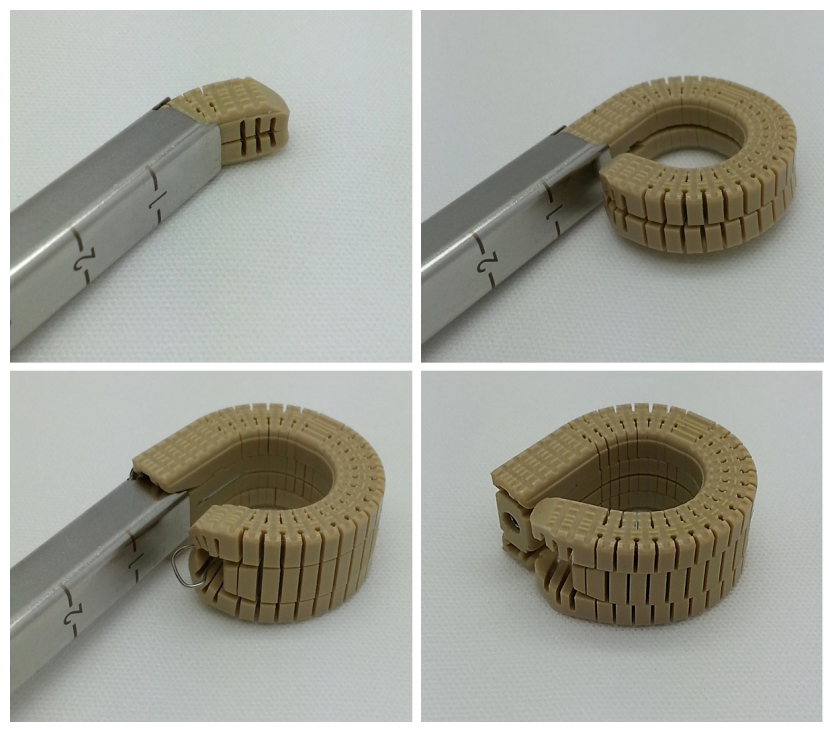

Fig. 4. Expandable TLIF cage surgical stages. A) interbody cage during deployment, B) cage fully deployed, C) cage expanded. 
extension motion, from $7.4 \pm 1.8$ degrees to $5.2 \pm 1.4$ degrees under no preload, $\mathrm{p}<0.01$, and from $7.4 \pm 1.6$ degrees to $2.9 \pm 0.8$ degrees under $400 \mathrm{~N}$ preload, $\mathrm{p}<0.01$ (Table 2). This represents a decrease in sagittal plane motion by $28 \%$ and $61 \%$, respectively (Figure 5 , Figure 6). The difference in the abilities of the deployable and expandable cages and control devices in limiting flexion-extension motion under the preload of $400 \mathrm{~N}$ was statistically equivalent (57\% vs. $61 \%$, $\mathrm{p}=0.31$ ). However, in the absence of compressive preload, the deployable and expandable TLIF cage was superior in limiting flexion-extension motion (53\% vs. $28 \%, \mathrm{p}=0.00)$.

In lateral bending, the deployable and expandable TLIF cage reduced motion from $8.0 \pm 1.5$ degrees to $4.1 \pm 1.5$ degrees, $\mathrm{p}<0.01$. This represents a decrease in coronal plane motion of $50 \%$. The control cage reduced motion from $8.9 \pm 1.9$ degrees to $3.9 \pm 1.7$ degrees, $\mathrm{p}<0.01$. This represents a reduction of coronal

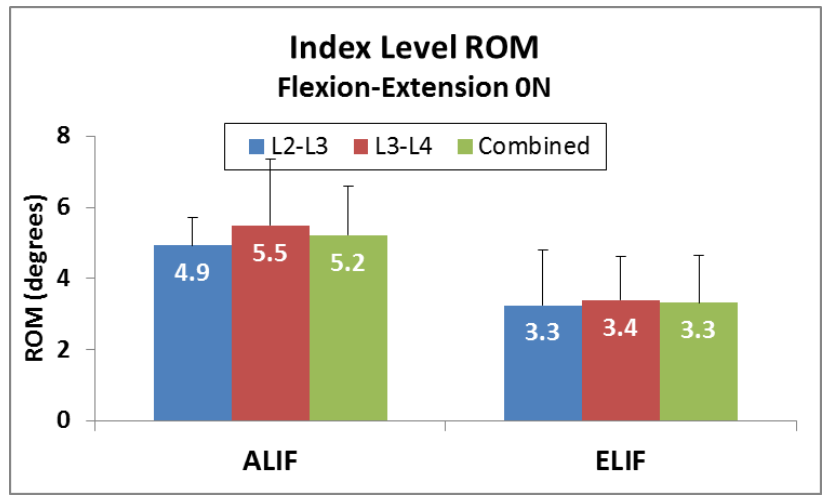

Fig. 5. Range of motion of ALIF and the expandable TLIF devices in both implanted segments (L2-L3 and L3-L4) in flexion-extension without preload.

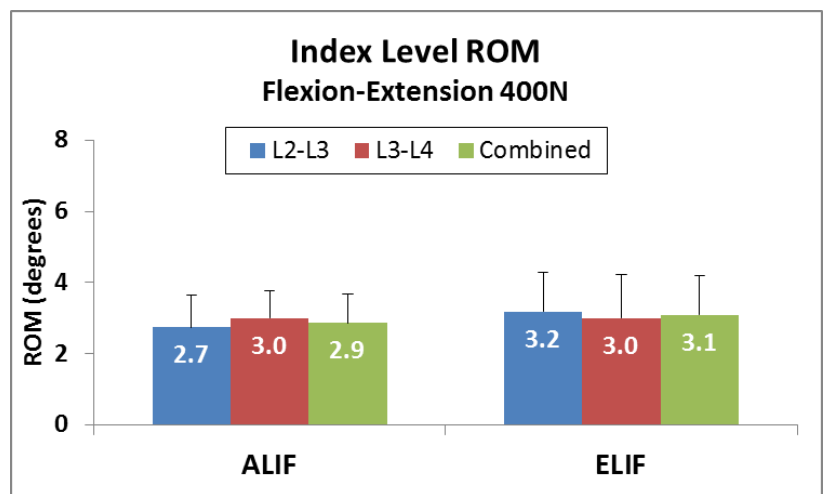

Fig. 6. Range of motion of ALIF and the expandable TLIF devices in both implanted segments (L2-L3 and L3-L4) in flexion-extension under 400N follower preload. plane motion of 56.4\% (Table $1 \&$ Table 2, Figure 7). There was no statistically significant difference in the abilities of the deployable and expandable cages and control devises in limiting lateral bending motion (50\% vs. $56 \%, \mathrm{p}=0.26)$.

In axial rotation, the deployable and expandable TLIF cage reduced range of motion from $2.4 \pm 1.4$ degrees to $1.5 \pm 0.5$ degrees, $\mathrm{p}<0.05$. This represents reduced motion in the axial plane by $21 \%$. The ALIF control cage reduced motion from $2.6 \pm 2.1$ to 1.6 \pm 0.9 degrees, $\mathrm{p}<0.05$. This represents reduced motion in the axial plane of $22 \%$ (Table $1 \&$ Table 2, Figure 8). The difference in the abilities of the deployable and expandable cages and control devices in limiting axial rotation motion was statistically equivalent $(21 \%$ vs. $22 \%, \mathrm{p}=0.94)$.

Table 1. Segmental Range of motion* (Mean \pm SD) with (experimental) TLIF cage (degrees).

\begin{tabular}{|l|r|r|r|r|r|}
\hline & Intact & TLIF & TLIF+PS & $\begin{array}{r}\text { \% Change } \\
\text { TLIF from } \\
\text { Intact }\end{array}$ & $\begin{array}{r}\text { \% Change } \\
\text { TLIF+PS from } \\
\text { Intact }\end{array}$ \\
\hline $\begin{array}{l}\text { Flexion- } \\
\text { Extension } \\
0 \mathrm{~N}\end{array}$ & $7.1 \pm 1.1$ & $3.3 \pm 1.3$ & $0.6 \pm 0.3$ & $-53 \pm 18 \%$ & $-91 \pm 3.9 \%$ \\
\hline $\begin{array}{l}\text { Flexion- } \\
\text { Extension } \\
400 \mathrm{~N}\end{array}$ & $7.1 \pm 1.1$ & $3.1 \pm 1.1$ & $0.6 \pm 0.2$ & $-57 \pm 14 \%$ & $-91 \pm 3.5 \%$ \\
\hline $\begin{array}{l}\text { Lateral } \\
\text { Bending }\end{array}$ & $8.0 \pm 1.5$ & $4.1 \pm 1.5$ & $1.1 \pm 0.4$ & $-50 \pm 16 \%$ & $-86 \pm 4.5 \%$ \\
\hline $\begin{array}{l}\text { Axial Ro- } \\
\text { tation }\end{array}$ & $2.4 \pm 1.4$ & $1.5 \pm 0.5$ & $0.7 \pm 0.2$ & $-21 \pm 40 \%$ & $-62 \pm 24 \%$ \\
\hline
\end{tabular}

${ }^{*}$ Reported ranges of motion are from combined L2-L3 and L3-L4 motion data.

Table 2. Segmental Range of motion* (Mean \pm SD) with (control) ALIF cage (degrees).

\begin{tabular}{|l|l|l|l|r|r|}
\hline & Intact & ALIF & ALIF+PS & $\begin{array}{r}\text { \% Change } \\
\text { ALIF from } \\
\text { Intact }\end{array}$ & $\begin{array}{r}\text { \% Change AL- } \\
\text { IF+PS from In- } \\
\text { tact }\end{array}$ \\
\hline $\begin{array}{l}\text { Flexion- } \\
\text { Extension } \\
0 N\end{array}$ & $7.4 \pm 1.8$ & $5.2 \pm 1.4$ & $0.8 \pm 0.3$ & $-28 \pm 15 \%$ & $-89 \pm 4.7 \%$ \\
\hline $\begin{array}{l}\text { Flexion- } \\
\text { Extension } \\
400 N\end{array}$ & $7.4 \pm 1.6$ & $2.9 \pm 0.8$ & $0.6 \pm 0.1$ & $-61 \pm 12 \%$ & $-92 \pm 1.9 \%$ \\
\hline $\begin{array}{l}\text { Lateral } \\
\text { Bending }\end{array}$ & $8.9 \pm 1.9$ & $3.9 \pm 1.7$ & $1.1 \pm 0.4$ & $-56 \pm 14 \%$ & $-88 \pm 3.4 \%$ \\
\hline $\begin{array}{l}\text { Axial Ro- } \\
\text { tation }\end{array}$ & $2.6 \pm 2.1$ & $1.6 \pm 0.9$ & $0.6 \pm 0.3$ & $-22 \pm 36 \%$ & $-66 \pm 22 \%$ \\
\hline
\end{tabular}

*Reported ranges of motion are from combined L2-L3 and L3-L4 motion data. 
Supplemental posterior fixation using bilateral pedicle screws and rods resulted in further reduction in ROM in flexion-extension, lateral bending, and axial rotation (Table $1 \&$ Table 2 ). The effect of supplemental fixation was significant compared to the stand-alone devices, for both TLIF and ALIF cages $(\mathrm{p}<0.01)$. Both devices, when used in conjunction with supplemental fixation, were statistically equivalent in their ability to reduce segmental motion in flexion-extension ( $p>0.22)$, lateral bending $(p=0.06)$, and axial rotation $(\mathrm{p}=0.61)$.

\section{Discussion}

This study compared the relative biomechanical stability between two implants of similar footprint size inserted using two different surgical approaches. ${ }^{2,3}$ The shape and size of the fully deployed and expanded TLIF cage is very similar to a traditional ALIF cage. Despite the fact that the anterior longitudinal ligament is removed during ALIF insertion, we chose not to compare to a traditional TLIF cage since the

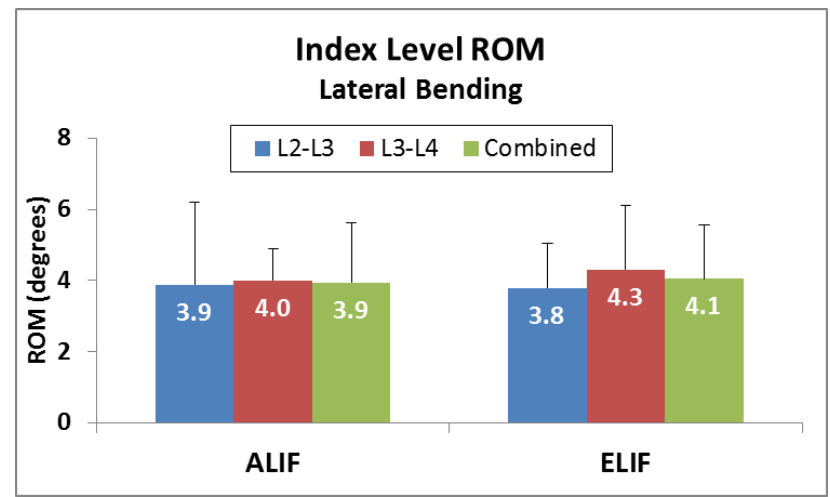

Fig. 7. Range of motion of ALIF and expandable TLIF devices in both implanted segments (L2-L3 and L3-L4) in lateral bending.

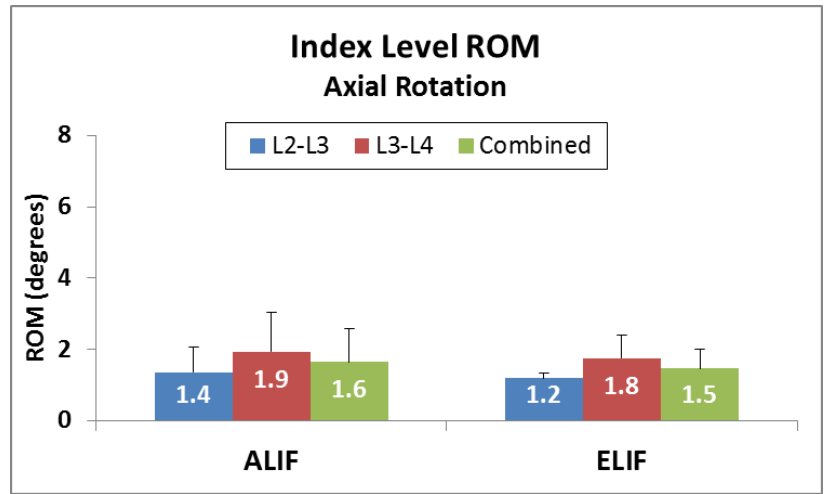

Fig. 8. Range of motion of ALIF and expandable TILF devices in both implanted segments (L2-L3 and L3-L4) in axial rotation. endplate coverage is much smaller than the deployable and expandable Luna cage. Therefore, both deployable and expandable TLIF cage and ALIF cages provide similar surface area for bone graft material, increased stiffness imparted by anterior column support, and the ability to restore sagittal alignment.

Lumbar interbody fusion utilizing a fusion cage with bone graft has benefits when compared to a posterolateral fusion technique. The benefits include greater surface area for bone graft-endplate interface, increased stiffness due to anterior column support, ${ }^{1}$ and the ability to restore alignment. Circumferential constructs consisting of an anterior cage and posterior instrumentation has been shown to improve fusion rates. ${ }^{20} \mathrm{~A}$ number of interbody technique have been described including ALIF, PLIF and TLIF; each with its own respective advantages and disadvantages. ${ }^{1-3}$ Posterior interbody fusion techniques when used in circumferential fusions have the advantage of a single approach..$^{1-3}$ However, the anatomy limits the size of the interbody device that can be inserted posteriorly. The anterior approach affords a larger implant footprint given the unencumbered path to the disk space. Grant and colleagues demonstrated that lumbar endplate density and cortical thickness increase as one approaches the periphery of the vertebral body which makes placement of a cage with larger surface area desirable. ${ }^{21}$

A deployable and expandable lumbar interbody fusion cage which allows for a single, minimally invasive, posterior approach and annulotomy with intervertebral deployment resulting in a broad-based footprint may improve outcomes and limit complication. The purpose of this study was to demonstrate biomechanical equivalency of this type of a device to a standard ALIF cage. The biomechanical stability of the deployable and expandable TLIF cage was found to be at least equivalent to the ALIF cage, both when used as stand-alone devices as well as when supplemented with bilateral pedicle screw-rod stabilization. Although neither implant is intended to be used as a stand-alone device, both implant types were tested as such in order to elucidate the stability imparted by the interbody device itself, independent of the posterior instrumentation. The in situ expandable nature of the cage after implantation allows for distraction 
of the disc space without violating endplates during insertion for the same cage size.

The two devices significantly reduced segmental motion at the level of implantation and $t$ no statistical difference between the devices in reducing flexionextension with compressive preload, lateral bending, or axial rotation was observed. Under flexionextension testing without preload, there was a statistically significant difference between the two devices favoring increased stability of the deployable and expandable TLIF cage. This is attributable to the retention of the anterior tension band and a small annular window of the TLIF approach through which the deployable and expandable device can be inserted prior to in situ expansion.

The compressive preload in the lumbar spine is caused by the action of muscles and has been shown to vary from a low value of $200 \mathrm{~N}$ during supine and lateral recumbent postures to over $1000 \mathrm{~N}$ during standing and walking. ${ }^{22}$ Therefore, the improved stability of the stand-alone deployable and expandable TLIF cage construct, compared to the stand-alone ALIF cage construct in the absence of a compressive preload may offer improved protection against migration during the low preload activities.

\section{Limitations}

As any cadaveric biomechanical investigation, our study has limitations. We compensated for the absence of active muscles by using follower preload (6-9). In this study our implantation levels of L2-L3 and L3-L4 were chosen in order to have similar anatomy (wedge angle, facet angulation) and kinematics at the two implanted levels. Utilizing L4-L5 would have been more clinically relevant but the lordosis and range of motion at L4-L5 is significantly different than at L3-L4.

\section{Conclusions}

The deployable and expandable Luna cage that can be inserted through TLIF approach with a small annular window and expanded axially in situ has the advantages of a single posterior approach and broad endplate footprint while retaining the anterior tension band for added stability. When compared to an
ALIF cage, the deployable and expandable TLIF cage demonstrates biomechanical equivalence in regards to segmental stability in the coronal, sagittal, and axial planes. The effect of this on fusion rate and decreased complications needs to be clinically studied.

The deployable and expandable TLIF cage is an improvement over traditional fixed dimension TLIF cages due to the implant's deployment technology making implantation possible through a narrow surgical corridor resulting in minimal nerve root retraction and tissue dissection. Additional benefits over traditional TLIF designs include a much larger endplate footprint and the ability to axially expand the device to add annular tension and segmental lordosis.

\section{Acknowledgements}

This study was supported by the Department of Veterans Affairs, Washington, DC, and Benvenue Medical, Santa Clara, CA.

\section{References}

1. Lee CS, Hwang CJ, Lee DH, et al. Fusion rates of instrumented lumbar spinal arthrodesis according to surgical approach: a systematic review of randomized trials. Clin Orthop Surg 2011;3:39-47.

2. Pannell WC, Savin DD, Scott TP, Wang JC, Daubs MD. Trends in the surgical treatment of lumbar spine disease in the United States. Spine J. 2015 Aug 1;15(8):1719-27.

3. Talia AJ, Wong ML, Lau HC, Kaye AH. Comparison of the different surgical approaches for lumbar interbody fusion. J Clin Neurosci. 2015

Feb;22(2):243-51.

4. Mobbs RJ, Loganathan A, Yeung V, Rao PJ. Indications for anterior lumbar interbody fusion. Orthop Surg. 2013 Aug;5(3):153-63.

5. Ahmadian A, Verma S, Mundis GM Jr, Oskouian RJ Jr, Smith DA, Uribe JS. Minimally invasive lateral retroperitoneal transpsoas interbody fusion for L4-5 spondylolisthesis: clinical outcomes. J Neurosurg Spine. 2013 Sep;19(3):314-20. doi: 10.3171/ 2013.6.SPINE1340. Epub 2013 Jul 26.

6. Billinghurst J, Akbarnia BA . Extreme lateral in-

Downloaded from http://ijssurgery.com/ by guest on April 26, 2023 
terbody fusion - XLIF . Curr Orthop Pract

2009;20:238-51 .

7. Harris BM, Hilibrand AS, Savas PE, et al. Transforaminal lumbar interbody fusion: the effect of various instrumentation techniques on the flexibility of the lumbar spine. Spine (Phila Pa 1976).

2004;29:E65-E70.

8. Phillips FM, Isaacs RE, Rodgers WB, Khajavi K, Tohmeh AG, Deviren V, Peterson MD, Hyde J, Kurd M. Adult degenerative scoliosis treated with XLIF: clinical and radiographical results of a prospective multicenter study with 24-month follow-up. Spine (Phila Pa 1976). 2013 Oct 1;38(21):1853-61.

9. Pimenta L, Turner AW, Dooley ZA, Parikh RD, Peterson MD. Biomechanics of lateral interbody spacers: going wider for going stiffer. ScientificWorld Journal. 2012;2012:381814. doi: 10.1100/2012/ 381814. Epub 2012 Nov 13.

10. Schwender JD, Holly LT, Rouben DP, Foley KT. Minimally invasive transforaminal lumbar interbody fusion (TLIF): technical feasibility and initial results. J Spinal Disord Tech. 2005;18(suppl 1):S1-S6.

11. Cannestra AF, Peterson MD, Parker SR, Roush TF, Bundy JV, Turner AW. MIS Expandable Interbody Spacers: A Literature Review and Biomechanical Comparison of an Expandable MIS TLIF With Conventional TLIF and ALIF. Spine (Phila Pa 1976). 2016 Apr;41 Suppl 8:S44-9. 12. Kunz D, Zdeblick T, McCabe R, et al. The effect of the mechanical environment on healing of a lumbar fusion using in an vivo model. 42 ${ }^{\text {nd }}$ Annual Meeting Orthopaedic Research Society, February 18-22, 1996, Atlanta, Georgia.

12. Perrin A, Cordey J. The concept of interfragmentary strain. Current Concepts of Internal Fixation of Fractures. Edited by Uhtoff, Berlin, SpringerVerlag, 1980.

13. Patwardhan AG, Havey RM, Meade KP, Lee B, Dunlap B: A Follower Load Increases the Load Carrying Capacity of the Lumbar Spine in Compression. Spine, 24(10):1003-9, 1999.

14. Patwardhan AG, Carandang G, Ghanayem A, Havey R, et al. Compressive preload improves the stability of the anterior lumbar interbody fusion (ALIF) cage construct. J Bone Joint Surg (Am), 2003 Sep;85-A(9):1749-56.
15. Phillips FM, Cunningham B, Carandang G, Ghanayem AJ, Voronov LI, Havey RM, Patwardhan AG. Effect of Supplemental Translaminar Facet Screw Fixation on the Stability of Stand-Alone ALIF Cages Under Physiologic Loads. Spine, 2004;29:1731-6.

16. Tzermiadianos MN, Mekhail A, Voronov LI, Zook J, Havey RM, Renner SM, Carandang G, Abjornson C, Patwardhan AG. Enhancing the stability of anterior lumbar interbody fusion: a biomechanical comparison of anterior plate versus posterior transpedicular instrumentation. Spine. 2008 Jan 15;33(2):E38-43.

17. Goel VK, Panjabi MM, Patwardhan AG, Dooris AP, Serhan H. Test Protocols for Evaluation of Spinal Implants. J Bone Joint Surg 2006;88-A (suppl. 2):103-109.

18. Suh $\mathrm{CH}$, Radcliffe $\mathrm{CW}$. Kinematics and Mechanisms Design. Malabar, FL: Krieger Publishing Company; 1983.

19. Fritzell P, Hagg O, Wessberg P, Nordwall A, Swedish Lumbar Spine Study G. Chronic low back pain and fusion: a comparison of three surgical techniques: a prospective multicenter randomized study from the Swedish lumbar spine study group. Spine 2002;27:1131-41.

20. Grant JP, Oxland TR, Dvorak MF. Mapping the structural properties of the lumbosacral vertebral endplates. Spine 2001;26:889-96.

21. Nachemson A. Lumbar intradiscal pressure. Experimental studies on post-mortem material. Acta Orthop Scand Suppl. 1960;43:1-104.

\section{Disclosures \& COI}

This study was suppported by the Department of Veterans Affairs, Washington, DC, and Benvenue Medical, Santa Clara, CA. Bartosz Wojewnik, MD, is a consultant for Synthes Spine.

\section{Corresponding Author}

Avinash G. Patwardhan, PhD, Department of Orthopaedic Surgery and Rehabilitation, Loyola University Chicago, 2160 S. First Avenue, Maywood, IL 60153, USA. apatwar@lumc.edu.

Published 1 August 2017. 
This manuscript is generously published free of charge by ISASS, the International Society for the Advancement of Spine Surgery. Copyright ๑ 2017
ISASS. To see more or order reprints or permissions, see http://ijssurgery.com. 